УДК 66.022.389

ПОЛУЧЕНИЕ НЕФТЯНЫХ СПЕКАЮЩИХ ДОБАВОК

В ПРОЦЕССАХ ГЛУБОКОЙ ВАКУУМНОЙ ПЕРЕГОНКИ

И ОКИСЛЕНИЯ

\title{
OBTAINING PETROLEUM SINTERING ADDITIVES IN THE OXIDATION PROCESS
}
Р.Р. Валинуров, А.Ш. Фазылов, Д.Ф. Осипенко, А.Ф. Ахметов, В.П. Запорин, В.П. Лосев

Уфимский государственный нефтяной технический университет, г. Уфа, Российская Федерация

Radim R. Valinurov, Azat Sh. Fazilov, Danil F. Osipenko, Arslan F. Akhmetov, Viktor P. Zaporin, Viktor P. Losev

Ufa State Petroleum Technological University, Ufa, Russian Federation e-mail: v_radim@mail.ru

Аннотация. В статье рассматривается проблема производства спекающих добавок к угольным шихтам из тяжелых остатков переработки нефти. В качестве сырья для исследования взят вакуумный остаток висбрекинга гудронов западно-сибирских нефтей. Для оценки возможности получения нефтепродукта, обладающего свойствами, позволяющими применять его в качестве спекающей добавки к угольным шихтам, остаток висбрекинга подвергался глубокой вакуумной перегонке на лабораторной установке AutoMaxx 9400 и окислению в реакторе периодического действия. Изучены физико-химические свойства полученных продуктов, в частности температура размягчения, плотность, спекающая способность, компонентный состав, пенетрация, произведено сравнение их с требуемыми показателями качества нефтяных спекающих добавок, определенными 
опытным путем и приведенными в работах И.Р. Хайрудинова. Произведено сравнение нефтепродуктов, полученных двумя способами: глубокой вакуумной перегонкой и окислением вакуумных остатков висбрекинга. Оценена возможность промышленного производства нефтяных спекающих добавок, приведены ожидаемые проблемы при производстве изученными способами.

Abstract: The article deals with the problem of production of sintering additives to coal charges from heavy residues of oil refining. The tars visbreaking vacuum residue of West Siberian oils was taken as a raw material for the study. To assess the possibility of obtaining a petroleum product with properties that make it possible to use it as a sintering additive to coal charges, the visbreaking residue was subjected to deep vacuum distillation in an AutoMaxx 9400 laboratory setup and oxidized in a batch reactor. The physicochemical properties of the obtained products were studied, in particular, the softening temperature, density, sintering capacity, component composition, penetration, they were compared with the required quality indicators of oil sintering additives, determined empirically and given in the works of I.R. Khairudinova. Comparison of two methods of obtaining oil sintering additives is made: deep vacuum distillation and oxidation of vacuum residues of visbreaking. The possibilities of industrial production, oil sintering additives are estimated, the expected problems in the production by the studied methods are given.

Ключевые слова: висбрекинг; коксование; коксохимия; мальтены; нефтепереработка; нефтяные спекающие добавки; окисление; спекание угля; угольная шихта

Keywords: visbreaking; coking; coke chemistry; maltenes; oil refining; oil sintering additives; oxidation; sintering of coal; coal charge 
Перспективы развития нефтеперерабатывающей промышленности невозможно представить без глубокой переработки самой тяжелой части нефти - нефтяных остатков и их рационального использования. Крупным потребителем продуктов, близких по составу и свойствам к нефтяным остаткам, является металлургическая промышленность, где используются продукты углепереработки. Наиболее перспективными для применения в коксохимии являются следующие нефтепродукты: вакуумный остаток первичной переработки нефти - гудрон, асфальт деасфальтизации гудрона, остатки крекинга и тяжелые смолы пиролиза.

В настоящее время из этих нефтепродуктов производятся следующие товарные продукты: котельное топливо (мазут); битум - дорожный, строительный и специальный; нефтяные связующие вещества - пеки; нефтяные коксы, углеродные волокна и технический углерод (сажа) из нефтяного сырья. Производство котельного топлива является наиболее нерациональным способом переработки нефтяного сырья.

При переработке тяжелых нефтяных остатков помимо технологических задач по производству перед нефтяной отраслью стоит задача реализации полученных продуктов. По причине отсутствия перспективных направлений использования тяжелых нефтяных остатков в топливном направлении необходимо обратить внимание на коксохимическую промышленность, где долгие годы наблюдается проблема дефицита коксующихся и спекающихся марок углей.

Основной отличительной особенностью спекающих и коксующихся углей является высокое содержание конденсированных ароматических структур, образующих при нагревании мезофазу, которая растекается и связывает частички угля, образуя коксовый пирог [1, 2].

Возможность применения нефтепродуктов в качестве компонентов угольной шихты долгое время изучалось учеными, однако применение нашли только нефтяные коксующие добавки, производство которых организовано в ряде установок замедленного коксования $[3,4]$. Коксующие 
добавки частично заменяют коксующиеся марки углей, однако дефицит спекающих углей остается без внимания. Разработка технологии получения спекающих добавок на основе нефтяных остатков позволит дополнительно расширить сырьевую базу коксохимии за счет вовлечения большего количества слабоспекающихся и неспекающихся марок углей [5-7].

Для сравнения различных способов получения нефтяных спекающих добавок проведен ряд экспериментов по оценке влияния, глубины вакуумной перегонки и окисления на вакуумный остаток процесса висбрекинга.

В качестве исходного сырья для получения спекающей добавки использовался вакуумный остаток висбрекинга, наиболее близкий к мезогенной части углей.

Для корректного сравнения влияния глубины вакуумной перегонки и процесса окисления в качестве сырья использовали вакуумный остаток висбрекинга из одной партии с одинаковыми физико-химическими свойствами, приведенными в таблице 1.

В связи с принципиальным различием методов получения спекающих добавок было принято решение оценить возможность и рентабельность получения спекающих добавок тем или иным способом для полученных продуктов, доведенных до равной температуры размягчения по КиШ, $\approx 115^{\circ} \mathrm{C}$.

Для оценки возможности применения полученных остатков в качестве спекающих добавок в угольные шихты выбраны следующие физикохимические свойства: спекающая способность по методу Рога; слёживаемость - пенетрация; температура размягчения по «кольцу и шару»; коксуемость по методу Конрадсона.

Все исследования проводились на базе Уфимского государственного нефтяного технического университета. 
Таблица 1. Физико-химические свойства исходного вакуумного остатка висбрекинга.

\begin{tabular}{|l|c|c|}
\hline \multicolumn{1}{|c|}{ Показатель } & Метод испытания & Значение \\
\hline Плотность, $\rho_{4}^{20}$ & ГОСТ 3900 & 1027 \\
\hline Вязкость условная при $80{ }^{\circ} \mathrm{C},{ }^{\circ} \mathrm{BУ}$ & ГОСТ 6258 & 295 \\
\hline Температура вспышки в открытом тигле, ${ }^{\circ} \mathrm{C}$ & ГОСТ 4333 & 280 \\
\hline Коксуемость, $\%$ масс. & ГОСТ 19932 & 23,0 \\
\hline Содержание серы, $\%$ масс. & ГОСТ 32139 & 2,5 \\
\hline Температура начала кипения, ${ }^{\circ} \mathrm{C}$ & ГОСТ 2177 & 278 \\
\hline Температура размягчения по КИШ, ${ }^{\circ} \mathrm{C}$ & ГОСТ 32054 & 37 \\
\hline
\end{tabular}

При вакуумной перегонке остатков увеличивается доля смол, асфальтенов и карбидов, поэтому можно предположить, что в процессе вакуумной перегонки теоретически можно получить спекающие добавки.

Оценка влияния глубины вакуумной перегонки проводилась на лабораторной вакуумной установке AutoMaxx 9400 по ASTM D5236, исходное сырье - вакуумный остаток, подвергалось дополнительной глубокой разгонке под остаточным давлением 1,1-1,4 мм рт. ст., после чего определялись основные физико-химические свойства полученных глубоко вакуумных остатков. Результаты исследований приведены в таблице 2.

На основании полученных данных можно сделать вывод, что увеличение только лишь глубины вакуумной перегонки хотя и улучшает необходимые свойства пека, но этого недостаточно для получения спекающих добавок требуемого качества. Также принимая во внимание сложность и энергоемкость глубокой вакуумной дистилляции, а также отсутствие технологической возможности для обеспечения требуемой глубины вакуумной перегонки в промышленных масштабах на существующих технологических установках, можно резюмировать, что получение спекающих добавок путем глубокой вакуумной перегонки невозможно. 
Таблица 2. Физико-химические свойства пека висбрекинга различной глубины вакуумной перегонки.

\begin{tabular}{|c|c|c|c|c|}
\hline Показатель & $\begin{array}{c}\text { Нормативный } \\
\text { документ }\end{array}$ & Исходный & $500+{ }^{\circ} \mathrm{C}$ & $540+{ }^{\circ} \mathrm{C}$ \\
\hline 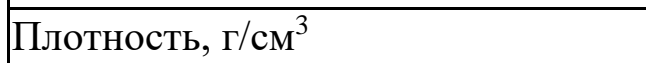 & ГОСТ 3900 & 1,0271 & 1,0337 & 1,0428 \\
\hline Давление процесса, мм рт. ст. & - & 40 & 1,4 & 1,1 \\
\hline $\begin{array}{l}\text { Температура размягчения по КиШ, } \\
{ }^{\circ} \mathrm{C}\end{array}$ & ГОСТ 32054 & 37 & 43 & 52 \\
\hline Пенетрация, ед. & ГОСТ 32154 & 250 & 78 & 27 \\
\hline Коксуемость по Конрадсону, \% & ГОСТ 19932 & 22,96 & 3107 & 33,65 \\
\hline Выход продукта, \% & - & 100 & 92,37 & 81,22 \\
\hline \begin{tabular}{|l} 
Компонентный состав: \\
- парафино-нафтеновые угв. \\
- легкая ароматика \\
- средняя ароматика \\
- тяжелая ароматика \\
- смолы 1 \\
- смолы 2 \\
- асфальтены
\end{tabular} & a.c. & $\begin{array}{c}13,6 \\
10,8 \\
4,7 \\
35,8 \\
9,4 \\
22,2 \\
3,5\end{array}$ & $\begin{array}{c}15,7 \\
13,4 \\
5,6 \\
30,5 \\
9,9 \\
21,2 \\
3,7\end{array}$ & $\begin{array}{c}12,7 \\
13 \\
6,1 \\
32,4 \\
10,9 \\
20,1 \\
4,7\end{array}$ \\
\hline
\end{tabular}

Рассмотрим поэтому второй способ получения спекающих добавок окисление нефтяных остатков.

Оценка влияния процесса термоокисления проводилась на лабораторной установке собственного производства, состоящей из реактора периодического действия, снабженного нагревательным элементом по внешней стороне стенки, трёхзонной термопары, автоматического регулятора температуры, компрессора для подачи воздуха, холодильника паров, сепаратора и газовых часов.

Для оценки влияния компонентного состава вакуумных остатков на свойства получаемых спекающих добавок в процессе окисления, помимо исходного сырья, были окислены глубоковакуумные остатки, полученные в процессе, описанном выше.

Исходный вакуумный остаток висбрекинга, глубоковакуумные остатки с температурой начала кипения $500+{ }^{\circ} \mathrm{C}$ и $540+{ }^{\circ} \mathrm{C}$ при неизменных параметрах процесса: загрузка - 1,5 л; температура в реакторе $-230{ }^{\circ} \mathrm{C}$; расход воздуха - 5 л/мин подвергались окислению. 
Контрольное свойство продукта - температура размягчения по методу «кольцо и шар» определялось во время процесса с периодичностью 1 раз в час. После достижения температуры размягчения по КиШ $115{ }^{\circ} \mathrm{C}$ окисление прекращалось, продукт сливался из реактора, и изучались физико-химические свойства полученных остатков, приведены в таблице 3.

Таблица 3. Физико-химические свойства спекающих добавок, полученных в процессе окисления

\begin{tabular}{|c|c|c|c|c|}
\hline Показатель & \multicolumn{4}{|c|}{ Время окисления } \\
\hline \multicolumn{5}{|c|}{ Исходный продукт с температурой начала кипения $278^{\circ} \mathrm{C}$} \\
\hline Время окисления, ч & 0 ' & $3^{\prime}$ & 5 & $6 ?$ \\
\hline $\begin{array}{l}\text { Температура размягчения } \\
\text { по КиШ, }{ }^{\circ} \mathrm{C}\end{array}$ & 37 & 72 & 95 & 115 \\
\hline Пенетрация, ед. & 250 & 47 & 11 & 7 \\
\hline \multicolumn{5}{|c|}{ Вакуумный остаток $500+{ }^{\circ} \mathrm{C}$ полученный из исходного продукта } \\
\hline Время окисления, ч & 0 ' & 4'30”' & 5'30” & 6' $15^{\prime \prime}$ \\
\hline $\begin{array}{l}\text { Температура размягчения } \\
\text { по КиШ, }{ }^{\circ} \mathrm{C}\end{array}$ & 43 & 88 & 101 & 115 \\
\hline Пенетрация, ед. & 250 & 23 & 14 & 7 \\
\hline \multicolumn{5}{|c|}{ Вакуумный остаток $540+^{\circ} \mathrm{C}$ полученный из исходного продукта } \\
\hline Время окисления, ч & 0 ' & 2 & 4'15” & 6'30" \\
\hline $\begin{array}{l}\text { Температура размягчения } \\
\text { по КиШ, }{ }^{\circ} \mathrm{C}\end{array}$ & 52 & 77 & 97 & 115 \\
\hline Пенетрация, ед. & 250 & 28 & 21 & 8 \\
\hline
\end{tabular}

В зависимости от глубины вакуумной перегонки, при которой получены остатки, и их первоначальной температуры размягчения для доведения их до требуемой температуры размягчения $115{ }^{\circ} \mathrm{C}$ потребуется от 6 до 6,5 ч.

Несмотря на ожидаемое сокращение времени окисления глубоковакуумных остатков, по причине увеличения доли легких смол и асфальтенов, время окисления увеличивается прямо пропорционально температуре начала кипения вакуумного остатка. Это связано, в первую очередь, с повышенным закоксовыванием маточника подачи воздуха в реактор. С этой проблемой сталкиваются и при производстве битума из высоковязких нефтей и нефтепродуктов [8].

Таким образом, можно сделать вывод о возможности получения окисленных пеков с требуемой температурой размягчения, 
обеспечивающей хорошую дробимость и отсутствие слеживаемости при транспортировке железнодорожным транспортом в летнее время года, и нецелесообразности чрезмерно глубокой вакуумной перегонки остатка висбрекинга.

Для дальнейшего определения возможности применения полученных окисленных остатков в качестве спекающих добавок в угольные шихты коксования, была определена их способность спекать эталонный антрацит в соотношении $1: 5$ и 1: 7 (спекающая способность по методу Рога), полученные результаты приведены в таблице 4.

Таблица 4. Сравнение спекающей способности полученных остатков

\begin{tabular}{|l|c|c|c|c|}
\hline \multicolumn{1}{|c|}{ Показатель } & $\begin{array}{c}\text { Исходный } \\
\text { продукт }\end{array}$ & $\begin{array}{c}\text { Исходный } \\
\text { (окисленный) }\end{array}$ & $\begin{array}{c}500+ \\
\text { (окисленный) }\end{array}$ & $\begin{array}{c}540+ \\
\text { (окисленный) }\end{array}$ \\
\hline $\begin{array}{l}\text { Температура } \\
\text { размягчения по КиШ, }{ }^{\circ} \mathrm{C}\end{array}$ & 37 & 115 & 115 & 115 \\
\hline $\begin{array}{l}\text { Спекающая способность } \\
\text { по методу Рога ГОСТ }\end{array}$ & & & & \\
$\begin{array}{l}\text { ISO 15585-2013, } \\
\text { при соотношении остатка }\end{array}$ & & & & \\
к антрациту: & - & 84,5 & 86,7 & 88,7 \\
$1: 5$ & - & 61,7 & 62,45 & 65,9 \\
\hline
\end{tabular}

\section{Выводы}

1. Исходный пек, полученный в процессе висбрекинга, не проявил спекающих свойств, в то время как окисленные остатки показали многообещающие результаты, что превышает установленную минимальную спекающую способность - более 50 ед. [9].

2. Наибольшей спекающей способностью (88,7 ед.) обладает добавка, полученная окислением вакуумного остатка $540+{ }^{\circ} \mathrm{C}$, далее спекающая способность снижалась в прямо пропорциональной зависимости от глубины вакуумной перегонки. Так, наименьшей спекающей способностью (84,5 ед.) обладает окисленный остаток висбрекинга. Различие составило порядка 4,2 
ед., что несущественно, если принять во внимание затраты на глубокую вакуумную перегонку.

3. Таким образом, при сравнении спекающих добавок, полученных двумя способами, стало ясно, что приоритетным процессом производства спекающих добавок является термоокисление тяжелых нефтяных остатков.

\section{Список используемых источников}

1. Ольферт А.И., Фасенко К.А., Америк Ю.Б. Мезогенные нефтяные продукты в качестве спекающего компонента угольных композиций // Кокс и химия. 1986. № 3. С. 7-12.

2. Ольферт А.И., Сухов Е.А. Спекание углей в присутствии мезогенных углеводородных веществ // Кокс и химия. 1987. № 9. С. 6-13.

3. Вафин А.И., Запорин В.П. Выбор схемы глубокой переработки сернистой нефти с получением добавки коксующей // Вестник молодого ученого УГНТУ. 2015. № 2 (2). С. 51-57.

4. Варфоломеев Д.Ф., Хайрудинов И.Р., Галеев Р.Г. Перспективы производства и применения нефтяных спекающих добавок при получении металлургического кокса из шихт с повышенным содержанием слабоспекающихся и неспекающихся углей. М.: ЦНИИТЭнефтехим, 1990. $38 \mathrm{c}$.

5. Хайрудинов И.Р., Садыков Р.Х., Галеев Р.Г. Применение нефтяной спекающей добавки в производстве кокса // Кокс и химия. 1988. № 9. С. 11-12.

6. Васильев Ю.С., Дроздник И.Д., Юрина Л.В. Применение нефтяных спекающих добавок в шихтах коксования // Кокс и химия. 1989. № 12. С. 4- 6.

7. Ольферт А.И., Нешин Ю.И., Еник Г.И. Промышленные коксования угольной шихты пониженной спекаемости с нефтяной спекающей добавкой НСД-2 // Кокс и химия. 1990. № 10. С. 10-12.

8. Максимов М.В., Анищенко О.В. Способ повышения эффективности процесса получения окисленного битума // Молодой ученый. 2018. № 14 (200). C. 8-9. 
9. Хайрудинов И.Р. Производство нефтяной спекающей добавки - новое направление глубокой переработки сернистых нефтяных остатков // Сб. тр. БашНИИНП. Уфа: БашНИИНП, 1988. С. 116-123.

\section{References}

1. Olfert A.I., Fasenko K.A., Amerik Yu.B. Mezogennye neftyanye produkty v kachestve spekayushchego komponenta ugol'nykh kompozitsii [Mesogenic Petroleum Products as a Sintering Component of Coal Compositions]. Koks $i$ khimiya - Coke and Chemistry, 1986, No. 3, pp. 7-12. [in Russian].

2. Olfert A.I., Sukhov E.A. Spekanie uglei v prisutstvii mezogennykh uglevodorodnykh veshchestv [Sintering of Coals in the Presence of Mesogenic Hydrocarbon Substances]. Koks i khimiya - Coke and Chemistry, 1987, No. 9, pp. 6-13. [in Russian].

3. Vafin A.I., Zaporin V.P. Vybor skhemy glubokoi pererabotki sernistoi nefti s polucheniem dobavki koksuyushchei [Selection of a Scheme for Deep Processing of Sulphurous Oil with Obtaining a Coking Additive]. Vestnik molodogo uchenogo UGNTU - Vestnik Molodogo Uchenogo USPTU, 2015, No. 2 (2), pp. 51-57. [in Russian].

4. Varfolomeev D.F., Khairudinov I.R., Galeev R.G. Perspektivy proizvodstva i primeneniya neftyanykh spekayushchikh dobavok pri poluchenii metallurgicheskogo koksa iz shikht $s$ povyshennym soderzhaniem slabospekayushchikhsya $i$ nespekayushchikhsya uglei [Prospects for the Production and Use of Petroleum Sintering Additives in the Production of Metallurgical Coke from Charges with an Increased Content of Low-Sintering and Non-Sintering Coals]. Moscow, TsNIITEneftekhim Publ., 1990. 38 p. [in Russian].

5. Khairudinov I.R., Sadykov R.Kh., Galeev R.G. Primenenie neftyanoi spekayushchei dobavki v proizvodstve koksa [The Use of Petroleum Sintering Additives in the Production of Coke]. Koks i khimiya-Coke and Chemistry, 1988, No. 9, pp. 11-12. [in Russian]. 
6. Vasilev Yu.S., Drozdnik I.D., Yurina L.V. Primenenie neftyanykh spekayushchikh dobavok v shikhtakh koksovaniya [Application of Oil Sintering Additives in Coking Mixtures]. Koks i khimiya - Coke and Chemistry, 1989, No. 12, pp. 4-6. [in Russian].

7. Olfert A.I., Neshin Yu.I., Enik G.I. Promyshlennye koksovaniya ugol'noi shikhty ponizhennoi spekaemosti s neftyanoi spekayushchei dobavkoi NSD-2 [Industrial Coking of Coal Charge of Reduced Sintering Capacity with Oil Sintering Additive NSD-2]. Koks i khimiya - Coke and Chemistry, 1990, No. 10, pp. 10-12. [in Russian].

8. Maksimov M.V., Anishchenko O.V. Sposob povysheniya effektivnosti protsessa polucheniya okislennogo bituma [Method for Increasing the Efficiency of the Oxidized Bitumen Production Process]. Molodoi uchenyi-Young Scientist, 2018, No. 14 (200), pp. 8-9. [in Russian].

9. Khairudinov I.R. Proizvodstvo neftyanoi spekayushchei dobavki - novoe napravlenie glubokoi pererabotki sernistykh neftyanykh ostatkov [Production of Oil Sintering Additive - a New Direction of Deep Processing of Sulphurous Oil Residues]. Sbornik trudov BashNIINP [Collection of Works of BashNIINP]. Ufa, BashNIINP Publ., 1988, pp. 116-123. [in Russian].

\section{Сведения об авторах}

\section{About the authors}

Валинуров Радим Рамилевич, аспирант кафедры «Технология нефти и газа», УГНТУ, г. Уфа, Российская Федерация

Radim R. Valinurov, Post-graduate Student of Oil and Gas Technology Department, USPTU, Ufa, Russian Federation

e-mail: v_radim@mail.ru 
Фазылов Азат Шамилевич, магистрант кафедры «Технология нефти и газа», УГНТУ, г. Уфа, Российская Федерация

Azat Sh. Fazilov, Undergraduate Student of Oil and Gas Technology Department, USPTU, Ufa, Russian Federation

e-mail: azat97@bk.ru

Осипенко Данил Федорович, аспирант кафедры «Технология нефти и газа», УГНТУ, г. Уфа, Российская Федерация

Danil F. Osipenko, Post-graduate Student of Oil and Gas Technology Department, USPTU, Ufa, Russian Federation

Ахметов Арслан Фаритович, д-р техн. наук, профессор, заведующий кафедрой «Технология нефти и газа», УГНТУ, г. Уфа, Российская Федерация

Arslan F. Akhmetov, Doctor of Engineering Sciences, Professor, Head of Oil and Gas Technology Department, USPTU, Ufa, Russian Federation

e-mail: tngrusoil@mail.ru

Запорин Виктор Петрович, канд. техн. наук, доцент кафедры «Технология нефти и газа», УГНТУ, г. Уфа, Российская Федерация

Viktor P. Zaporin, Candidate of Engineering Sciences, Assistant Professor of Oil and Gas Technology Department, USPTU, Ufa, Russian Federation e-mail: tngrusoil@mail.ru

Лосев Виктор Павлович, ведущий инженер кафедры «Технология нефти и газа», УГНТУ, г. Уфа, Российская Федерация

Viktor P. Losev, Candidate of Engineering Sciences, Lead Engineer of Oil and Gas Technology Department, USPTU, Ufa, Russian Federation

e-mail: tngrusoil@mail.ru 